Article

\title{
Individual Morphology and Habitat Structure Alter Social Interactions in a Range-Shifting Species
}

\author{
Zachary J. Cannizzo ${ }^{1, *}{ }^{\mathbb{D}}$, Sara K. Nix ${ }^{1}$, Isabel C. Whaling ${ }^{1}$ and Blaine D. Griffen ${ }^{2}$ \\ 1 Marine Science Program, School of the Earth, Ocean, and Environment, University of South Carolina, \\ Columbia, SC 29208, USA; nixsk@email.sc.edu (S.K.N.); iwhaling@email.sc.edu (I.C.W.) \\ 2 Department of Biology, Brigham Young University, Provo, UT 84602, USA; blaine_griffen@byu.edu \\ * Correspondence: cannizzz@email.sc.edu
}

Received: 11 October 2018; Accepted: 31 December 2018; Published: 5 January 2019

\begin{abstract}
Ecosystem engineers that serve as foundation species shape the ecology and behavior of the species which depend on them. As species shift their geographic ranges into ecosystems they have not previously inhabited, it is important to understand how interactions with novel foundation species alter their behavior. By employing behavioral assays and morphological analyses, we examined how individual morphology and foundation species structure impact the ritualistic aggression behavior of the range shifting mangrove tree crab Aratus pisonii between its historic and colonized habitats. Structure of the foundation species of the colonized salt marsh ecosystem increases the incidence and risk of this behavior over the historic mangrove habitat, potentially negating benefits of ritualizing aggression. Further, docks within the salt marsh, which are structurally analogous to mangroves, mitigate some, but not all, of the increased costs of performing ritualized aggression. Crabs in the salt marsh also had relatively larger claws than conspecifics from the dock and mangrove habitats, which has implications for the risk and outcomes of ritualized interactions. These changes to morphology and behavior highlight the impacts that foundation species structure can have on the morphology, ecology, and behavior of organisms and the importance of studying these impacts in range shifting species.
\end{abstract}

Keywords: agonistic behavior; analogous habitat; Aratus pisonii; colonized ecosystem; engineered structures; mangrove; physical ecosystem engineers; range shift; salt marsh

\section{Introduction}

Autogenic ecosystem engineers, organisms that change the environment or create habitat via their own physical structure [1], impact nearly every aspect of the ecology of organisms which depend on them. For those engineers which also act as ecosystem foundation species (i.e., coral in a reef, mangroves in a forest, etc.) [2,3], the ecologies of countless species have evolved to take advantage of and survive in the habitats they provide. Among the many aspects of an organism's ecology that are tied to foundation species, behavior may have one of the largest impacts on daily energetics and survival. Foundation species impact a range of behaviors from foraging in crabs [4], birds [5], and rodents [6] to predator avoidance in bivalves [7] and fish [8]. Such behaviors can have drastic effects on the long-term life history, ecology, and fitness of individuals and populations. However, mismatches in climate-mediated geographic shifting rates are causing some species to decouple their geographic ranges from those of the foundation species on which they have historically depended [9]. When this occurs, shifting species may colonize ecosystems where the foundation species differ from those to which they are adapted, a phenomenon that is expected to become more frequent with continued climate change $[9,10]$. While alterations in behavior are often a first response to changing conditions [11], structural and non-structural differences between historic and novel foundation species 
may themselves lead to an alteration of ecologically important behaviors [4,7]. Thus, understanding how the behaviors of range shifting species are impacted by interactions with novel foundation species is vital to understanding and predicting the outcomes and impacts of range shifts.

The mangrove tree crab Aratus pisonii serves as a model for examining the impacts of novel foundation species on behavior. The climate-mediated northward range expansion of this historically mangrove-associated arboreal crab has recently resulted in its colonization of the salt marshes of Florida and Georgia [12]. The foundation species in the salt marsh, the grass Spartina alterniflora, differs greatly in structure from mangrove trees leading to the alteration of numerous aspects of this crab's ecology, including behavior $[4,13,14]$. However, A. pisonii are also found on artificial boat docks within the salt marsh. Unlike S. alterniflora, which dominates the salt marsh ecosystem, docks provide a shaded habitat similar to the mangrove canopy and vertical pilings which resemble mangrove trunks. Further, docks mitigate many of the negative impacts this species experiences in the salt marsh, including behavioral changes [14]. Docks, while not themselves a foundation species, are a result of an allogenic ecosystem engineer (humans), which provides structure similar to autogenic engineers, thus altering the flow of resources [1]. Thus, for the purposes of simplicity, we refer to docks as "foundation structure". This combination of historic (mangroves) and novel (marsh grass) foundation species, along with a structural analogue to the historic foundation species (docks), allows for the ability to tease apart the impacts of differing structure on ecologically relevant behaviors.

One such ecologically relevant behavior is ritualistic aggression (or ritualized combat). Like many species, A. pisonii males engage in ritualistic aggression following a stereotypical sequential assessment model where individuals vary their behavior during an interaction from low to high cost until a winner emerges, allowing opponents to avoid physical injury by determining the likely winner of a fight without physical confrontation $[15,16]$. Animals use this type of behavior for a variety of vital functions, from courtship [17-19] and territory defense [20,21] to the establishment of social hierarchies [22-25]. In A. pisonii, this behavior allows for the low-cost establishment of a social hierarchy based on size and sex that provides for effective division of resources [16]. However, as A. pisonii climbs structures during rising tides to avoid aquatic predation (pers. observ., [26]), the structure on which the interaction occurs may determine the outcome, cost, risk, and sequence of this specific behavior. In particular, the minimal surface area provided by grass stalks in the salt marsh may make performing the behavior difficult or, if crabs are more likely to fall in water, dangerous. Either could have cascading effects for the ability of the population to establish their ecologically important social hierarchy.

The differing habitats where A. pisonii is found could also indirectly impact this behavior through alterations to crab morphology. In A. pisonii, the winner of ritualized interactions is largely determined by size and, to a lesser degree, relative claw size [16]. As in many species, ornamentation or weaponry (claws) are displayed throughout the interaction with relatively larger weapons signifying a higher probability of winning a physical confrontation and thus serving as a reliable way for competitors to assess their opponents' fighting ability before engaging in a potentially costly fight $[15,16,27]$. However, claw size in crabs is highly plastic [28]. Many factors related to habitat type can alter claw size, including a more carnivorous diet [29], which A. pisonii experiences on docks [14]. Thus, differences in claw morphology between habitats must be considered to fully understand the impact of habitat structure on the ritualistic aggression behavior of this crab.

We sought to determine whether the structure of foundation species impacts the ritualistic aggression behavior of male $A$. pisonii. To do so, we performed a variety of behavioral assays pitting crabs against similar-sized conspecifics originating from the same and other habitats on structures representative of each habitat. We also determined if and how claw morphology differs between habitats and, by pitting competitors from different habitats across structural types, how these morphological differences alter the ritualistic behavior and its outcomes. Ultimately, we hypothesized that both substrate structure and claw morphology would impact ritualistic aggression in A. pisonii. In particular, we expected that the minimal structure provided by marsh grasses would increase the likelihood of a competitor falling in water, thus increasing the riskiness of interactions, leading to a 
reduction in the incidence of ritualized aggression compared to other structure types. Further, we hypothesized that the relatively high rate of carnivory exhibited in the dock habitat [14] would lead to relatively larger claws resulting in a higher rate of victory over conspecific from the salt marsh and mangrove habitats, and that the victor of interactions between crabs from the marsh and mangrove would not be predictable by habitat of origin due to a lack of morphological differences.

\section{Methods}

\subsection{Crab Collection and Preparation}

While we have observed females engaging in the behavior, ritualistic aggression in A. pisonii is largely performed by males [16]. Thus, we exclusively examined the behavior of male crabs. All crabs were collected from either mangrove forests in and around Fort Pierce, FL or salt marsh habitat and docks in and around Saint Augustine, FL, USA (Table 1). Crabs were collected by hand and placed in individual compartments of a plastic tackle box for transport to the Smithsonian Marine Station at Fort Pierce, FL, USA. Opaque dividers were used during transport to prevent crabs from interacting. Throughout captivity, crabs were housed individually in aquaria $(22.8 \times 15.2 \times 16.5 \mathrm{~cm}, 1 \times \mathrm{w} \times$ h) which were separated by opaque dividers and contained a petri dish of seawater and fresh food (Rhizophora mangle leaves), both of which were changed every other day, within a building open to ambient outdoor temperatures. Given the short time crabs were housed prior to being assayed (see below), it is unlikely that the food provided impacted behavior. To minimize the potential impact of temperature on behavior, assays were always performed during the same time of day. Further, temperature in the building showed little day-to-day fluctuation $\left(\sim 2-4{ }^{\circ} \mathrm{C}\right)$ throughout the period that assays were performed. We measured the size of each crab (carapace width) to the nearest 0.1 $\mathrm{mm}$ and painted the back of each individual with a thin stripe of one of six colors of nail polish for identification. Previous work has shown no effect of more extreme marking (painting of the entire carapace with nail polish) on the behavior of this species $[4,14]$. Crabs were then allowed to acclimate for an additional $24 \mathrm{~h}$ before behavior was assayed (see below). After assaying behavior, we measured the height $(\mathrm{CH})$ and length $(\mathrm{CL})$ of the major claw (to the nearest $0.1 \mathrm{~mm}$ ) of each crab following the methods of [30]. Crabs were returned to their site of origin within one week of assay completion.

Table 1. Location and habitat of collection sites.

\begin{tabular}{ccc}
\hline Habitat & Site & Lat-Long \\
\hline Mangrove & Pepper Park & $27^{\circ} 29^{\prime} 42^{\prime \prime} \mathrm{N}$ \\
& & $80^{\circ} 18^{\prime} 12^{\prime \prime} \mathrm{W}$ \\
Mangrove & Round Island Park & $27^{\circ} 33^{\prime} 33^{\prime \prime} \mathrm{N}$ \\
& & $80^{\circ} 19^{\prime} 53^{\prime \prime} \mathrm{W}$ \\
Mangrove & Oslo Road & $27^{\circ} 35^{\prime} 14^{\prime \prime} \mathrm{N}$ \\
& & $80^{\circ} 21^{\prime} 55^{\prime \prime} \mathrm{W}$ \\
Mangrove & North Causeway & $27^{\circ} 28^{\prime} 28^{\prime \prime} \mathrm{N}$ \\
& & $80^{\circ} 19^{\prime} 12^{\prime \prime} \mathrm{W}$ \\
Salt marsh & $30^{\circ} 0^{\prime} 49^{\prime \prime} \mathrm{N}$ \\
& GTM NERR & $81^{\circ} 20^{\prime} 42^{\prime \prime} \mathrm{W}$ \\
Salt marsh & & $29^{\circ} 52^{\prime} 40^{\prime \prime} \mathrm{N}$ \\
& & $81^{\circ} 16^{\prime} 32^{\prime \prime} \mathrm{W}$ \\
Salt marsh & Anastasia State Park & $29^{\circ} 55^{\prime} 16^{\prime \prime} \mathrm{N}$ \\
& & $81^{\circ} 17^{\prime} 57^{\prime \prime} \mathrm{W}$ \\
Dock & Vilano Marsh & $30^{\circ} 07^{\prime} 57^{\prime \prime} \mathrm{N}$ \\
& & $81^{\circ} 23^{\prime} 08^{\prime \prime} \mathrm{W}$ \\
Dock & Palm Valley & $29^{\circ} 53^{\prime} 09^{\prime \prime} \mathrm{N}$ \\
& & $81^{\circ} 17^{\prime} 08^{\prime \prime} \mathrm{W}$ \\
Dock & $29^{\circ} 56^{\prime} 33^{\prime \prime} \mathrm{N}$ \\
& Yacht Club & $81^{\circ} 18^{\prime} 32^{\prime \prime} \mathrm{W}$ \\
\hline
\end{tabular}




\subsection{Aggression Assays}

To assess how ritualistic aggression behavior was impacted by the variable influences of habitat structure and morphological differences between habitats, we ran a suite of behavioral assays. To avoid any confounding factors of multiple testing, individual crabs were never used in more than one trial. Warner [16] reported that interactions among crabs in the mangrove were most likely to occur between individuals that were similar in size. Thus, for all assays, crabs were paired with another individual that differed in size by no more than $1.3 \mathrm{~mm}$ and all but four interactions involved crabs that differed in size by less than $1 \mathrm{~mm}$.

To understand the impact of source habitat on the ritualistic aggression behavior of A. pisonii, we first conducted behavioral assays in a small plastic aquarium $(17.5 \times 10.5 \times 10 \mathrm{~cm}, 1 \times \mathrm{w} \times \mathrm{h})$ which acted as a neutral surface (Figure 1). We assayed fifteen pairs of crabs from each habitat (n assays $=45$ ) pitting only individuals from the same habitats. To explore effects of habitat-specific differences in morphology, we also explored inter-habitat interactions in the neutral arena by performing 45 additional assays pitting individuals from different habitats (15 assays/habitat combination: dock $\mathrm{v}$ marsh, marsh $\mathrm{v}$ mangrove, mangrove $\mathrm{v}$ dock). For all trials, the pair of competitors were placed in the arena and allowed to interact under video recording for 10 minutes, ensuring that they were not disturbed by the presence of an observer. After each assay, crabs were returned to their respective aquaria.
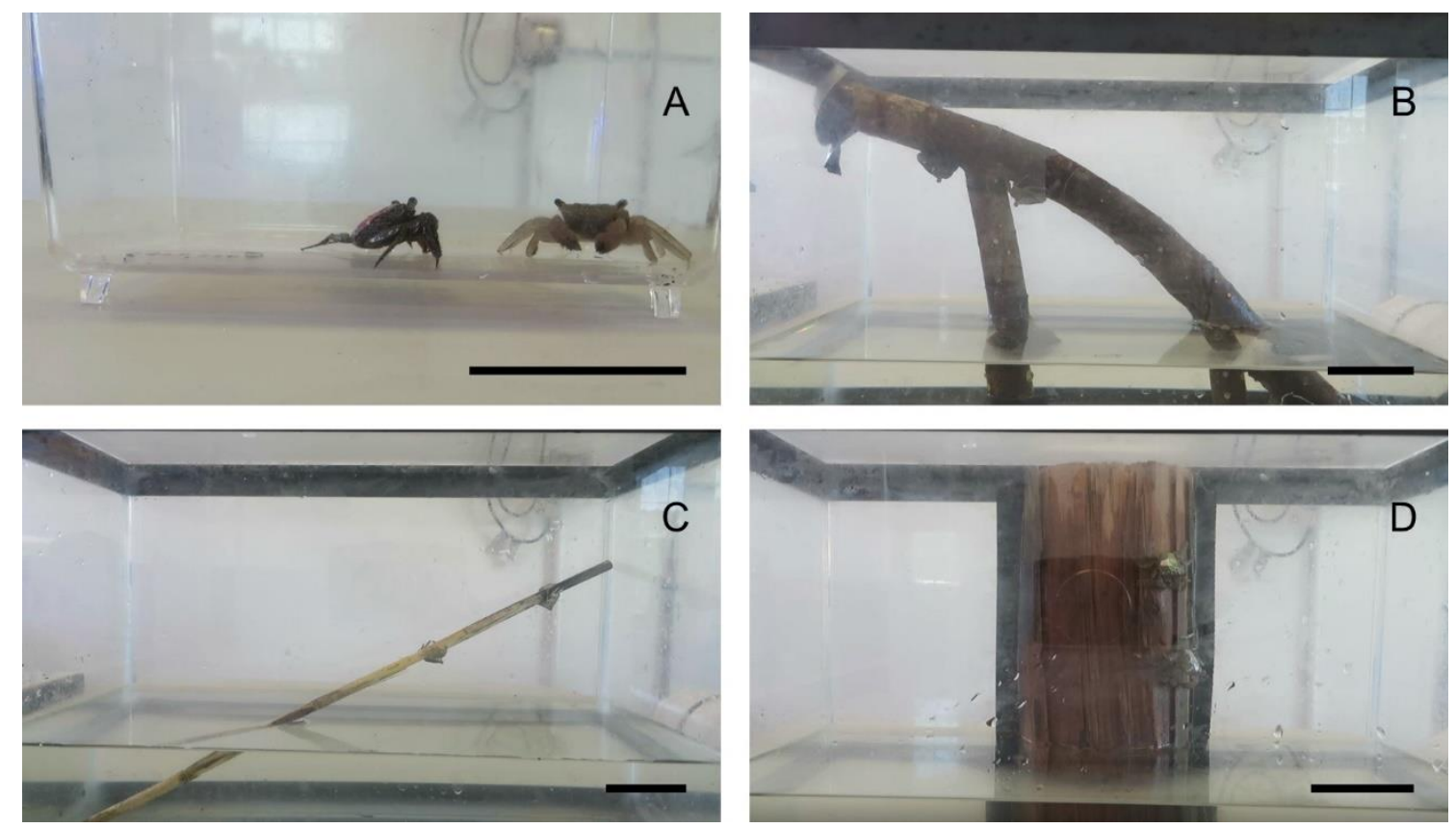

Figure 1. Representations of assays performed on (A) neutral structure, (B) mangrove structure, (C) salt marsh structure, and (D) dock structure. Scale bars represent $5 \mathrm{~cm}$.

We next sought to determine how the three foundation structures impacted ritual aggression behavior. Salt marsh structure was represented by a stalk of S. alterniflora, mangrove structure by a mangrove prop root, and dock structure by a rounded piece of weathered wood which resembled a piling (Figure 1). For each assay, the designated structure was placed in an aquarium $(50.0 \times 26.5 \times$ $30.5 \mathrm{~cm}, 1 \times \mathrm{w} \times \mathrm{h}$ ) with $7 \mathrm{~cm}$ of seawater to simulate high-tide conditions. Structures were placed to balance the desire to mimic the natural environment with the need to record both crabs throughout the trial: the grass stalk was laid diagonally across the tank while the prop root extended from the side and the dock piling was placed against the back (Figure 1). The larger aquarium used in the structure assays was necessary to fit the structure used. Further, while the aquarium itself was larger, the area of structure available to crabs was less than or similar to that available in the neutral surface assays 
performed in the smaller aquarium. For all structural assays, competitors were placed directly on the structure no more than $10 \mathrm{~cm}$ apart. We performed fifteen intra-habitat assays for each habitat type pitting pairs of competitors on the structure of their habitat of origin ( $\mathrm{n}$ assays $=45$ ). For inter-habitat assays, we performed sixteen trials for each habitat combination (n assays $=48$ ). In each inter-habitat structural assay, the pair of crabs was assigned to the habitat of one competitor. For example: for the trials pitting crabs from the salt marsh with conspecifics from docks, eight pairs were assayed on marsh structure while eight interacted on dock structure. These inter-habitat structural assays allowed us to explore how interactions were impacted by the effects of habitat-specific morphological differences and crab familiarity with structural type.

As A. pisonii occurs in high densities in all habitats, individuals regularly come into contact and are often forced to remain in close proximity (pers. obs.). Thus, the restricted area provided by tanks in this study (neutral and structural assays) reflected interaction conditions that mimic those found in nature in some respects. However, the confined tank space of all assays (neutral and structural) did restrict the ability of crabs to fully retreat and avoid repeated interactions. To prevent biasing our results with repeated interactions between competitors, we analyzed only the first interaction which occurred in each trial.

After all assays were completed, we analyzed the videos using the open source video analysis software Kinovea (www.kinovea.org). We first noted whether a ritualized aggression interaction occurred, defined as either crab displaying shield posturing, display, or fighting behavior (Table 2), and the winner of each interaction. As willingness to fight, and fight vigorously, may provide an advantage [16,31,32], we noted the instigator (the first crab to perform a behavior) in each trial. Further, to explore mechanistic changes in the behavior itself, we recorded the length of the interaction (from initiation of aggressive interaction to return to a behavior not a part of the ritualized progression), the presence/absence of each step in the ritual progression (Table 2), and the duration of any fighting behavior. Finally, to gain a relative measure of the danger of performing ritualistic aggression on each structure, we noted whether a competitor fell in the water.

Table 2. Ethogram of behaviors in the A. pisonii ritualized aggression progression. Adapted from [16].

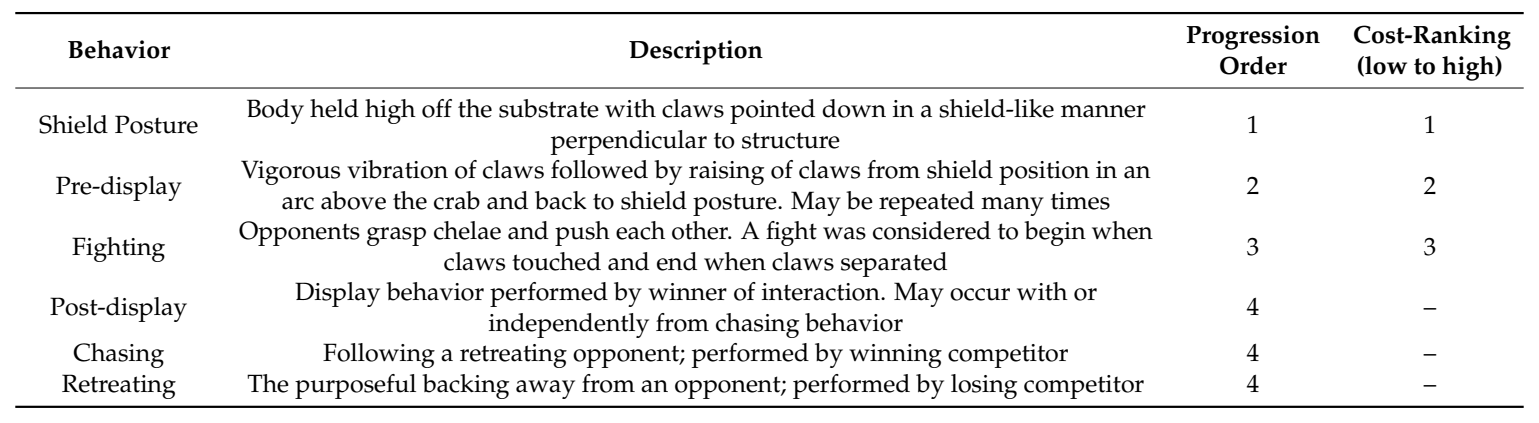

To examine the outcomes of interactions, we employed Chi-squared tests $\left(\mathrm{X}^{2}\right)$ to explore whether a crab was more likely to win if it was larger, had a larger relative $\mathrm{CL}$ and $\mathrm{CH}$, was collected from the structure type on which the assay was performed (mixed assays), or whether crabs from a certain habitat type were dominant (inter-habitat assays). We used additional $\mathrm{X}^{2}$ tests to examine whether the instigator of an interaction was more likely to win, whether the larger competitor was more likely to instigate, whether smaller crabs which instigated were more likely to win, and whether crabs from certain habitat types were more likely to instigate (inter-habitat assays)

We employed a binomial general linear model (GLM) to determine which variables impacted whether an interaction occurred during the assay. The explanatory variables for this model included structural type (mangrove, salt marsh, dock, none) as well as a number of morphological characteristics of the competitors: the difference in size between competitors, the absolute sizes of the two competitors, the residuals of the relationship between relative CL and size of both crabs, the residuals of the relationship between relative $\mathrm{CH}$ and size of both competitors, and the difference of each of those 
residual values between competitors. Unless otherwise stated, these explanatory variables, in addition to interaction duration, were used in all subsequent linear models. Residuals were used when morphological variables co-varied with crab size (LM; $p<0.05)$. To gain a mechanistic understanding of how the behavior changed, we also ran binomial GLMs to determine which variables impacted whether each behavior in the behavioral progression occurred (Table 2), and LMs to determine which of the explanatory variables, excluding interaction duration, impacted the duration of fights and the length of the interaction. Additional binomial GLMs were also employed to determine how structure and morphology impacted the likelihood of the larger competitor winning and of a crab falling into the water (structure assays only).

\subsection{Claw Morphology}

To compare A. pisonii claw morphology between habitats ( $\mathrm{n}=139,146$, and 136 for dock, mangrove, and salt marsh respectively), we used linear models (LM) to determine the relationships between a crab's carapace width and its $\mathrm{CL}, \mathrm{CH}$, and $\mathrm{CH}: \mathrm{CL}$ ratio. Habitat of origin was also included in the model to determine how relative claw size differed between habitats.

All LMs and GLMs were performed using the "lme4" package in R version 3.1.1 (R core team, $\mathrm{R}$ foundation for Statistical Computing, Vienna, Austria). We then used the "step" function to determine the simplest fitted model by AIC for each LM and GLM.

\section{Results}

\subsection{Aggression Assays}

For simplicity, here we present only the linear model (LM and GLM) results of those variables found to have a significant effect in the simplest model (by AIC). Full statistical results of the simplest models can be found in Supplementary Table S1. Foundation structure impacted a number of aspects of ritualistic aggression in A. pisonii. Interactions were both shorter (estim. $=28.803, \mathrm{z}=2.298, p=0.023$ ) and less likely to occur (estim. $=1.130, \mathrm{z}=2.603, p=0.009$ ) on dock structure than on a neutral surface. Further, interactions were more likely on salt marsh structure compared to both dock (estim. $=-1.618, \mathrm{z}=-2.759, p=0.006$ ) and mangrove structure (estim. $=-1.312, \mathrm{z}=-2.050, p=0.040$ ). In addition to altering the occurrence of interactions, the structure on which crabs engaged in ritualized aggression impacted the behavior itself. Competitors were more likely to skip the low-cost shield posture behavior and move directly to higher cost behaviors on dock (estim. $=-2.552, \mathrm{z}=-2.171$, $p=0.030$ ), salt marsh (estim. $=-2.580, \mathrm{z}=-2.241, p=0.025$ ), and neutral structures (estim. $=-2.156$, $\mathrm{z}=-1.986, p=0.047$ ) than on mangrove structure. After a winner was determined, the winner was then less likely to display on dock structure compared to mangrove (estim. $=2.131, \mathrm{z}=2.528, p=0.012$ ) and neutral surfaces (estim. $=1.701, \mathrm{z}=2.665, p=0.008$ ) while the loser was more likely to retreat on mangrove structure than salt marsh (estim. $=-2.805, \mathrm{z}=-2.448, p=0.014$ ) and neutral surfaces (estim. $=-2.271, \mathrm{z}=-2.097, p=0.036$ ), suggesting that display may trigger this conciliatory behavior. Further, interactions were more likely to result in a competitor falling in the water, increasing the danger of the interaction, when performed on dock (estim. $=-3.825, \mathrm{z}=-3.063, p=0.002$ ) or salt marsh structure (estim. $=-4.533,-3.524, p<0.001$ ) than on mangrove. In addition, there was no advantage to individuals that were captured on the same type of structure where interactions occurred $\left(\mathrm{X}^{2}{ }_{1}=0.067, p=0.414\right.$; Figure 2). 


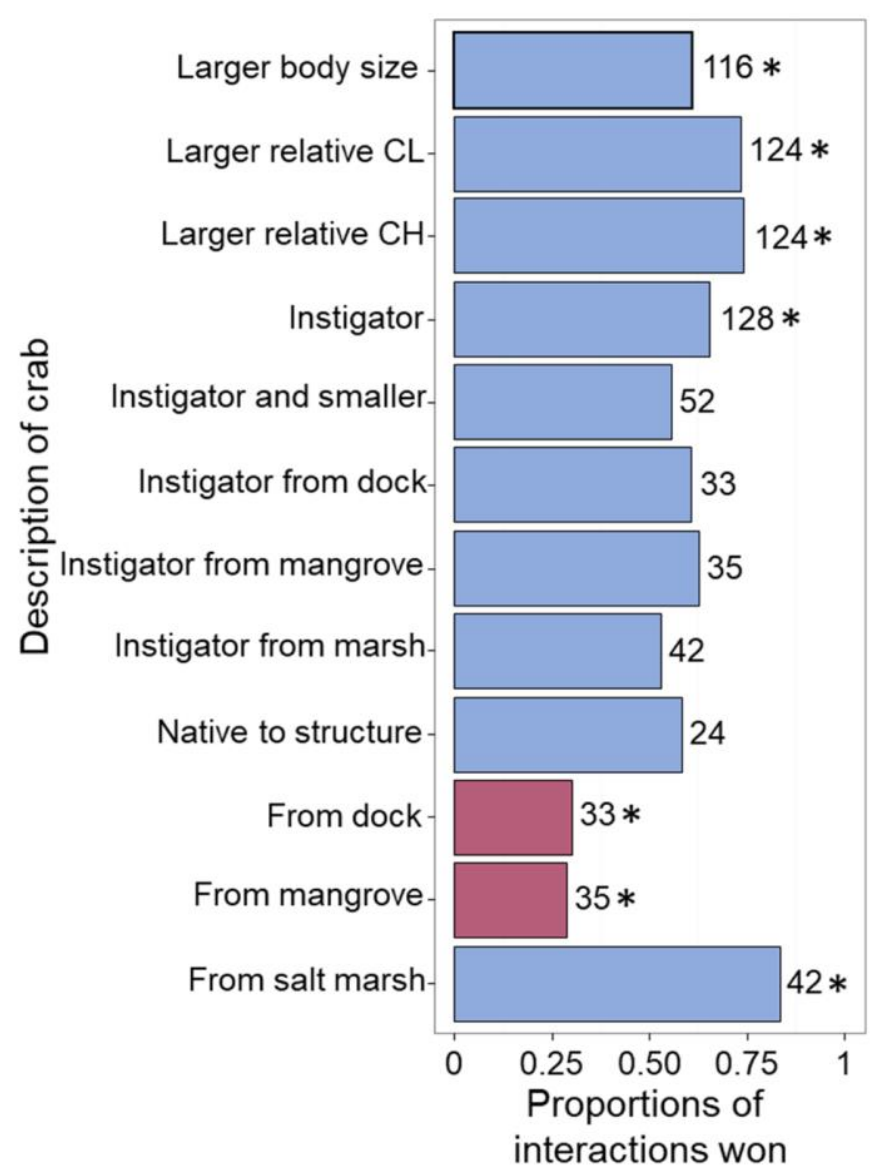

Figure 2. Proportion of interactions won by a variety of categories of competitor. Numbers represent the number of interactions examined while asterisks $\left(^{*}\right)$ represent significant effects $(\alpha=0.05)$. Blue bars represent proportions above 0.5 while red bars represent those below 0.5 .

Crab morphology also had numerous effects on ritualistic aggression. While morphology did not impact the length or occurrence of interactions, it altered many aspects of the ritual progression. Morphology of the smaller competitor was particularly impactful, as CL was inversely correlated with the likelihood of shield posturing (estim. $=-2.438, \mathrm{z}=-2.042, p=0.041$ ), and body size was positively correlated with the likelihood of pre-fight displays (estim. $=0.271, \mathrm{z}=2.885, p=0.004$ ). Further, retreat was more likely as the $\mathrm{CH}$ of the smaller competitor increased (estim. $=1.591, \mathrm{z}=1.970, p=0.049$ ). In contrast, the morphology of the larger crab affected only post-interaction display, which was more likely as its body size increased (estim. $=0.219, \mathrm{z}=2.117, p=0.034$ ). Morphology also affected the outcomes of interactions, as crabs were more likely to be victorious if they had a larger body size $\left(\mathrm{X}^{2}{ }_{1}=5.828, p=0.016\right.$; Figure 2$)$, a larger relative $\mathrm{CL}\left(\mathrm{X}^{2}{ }_{1}=27.129, p<0.001\right.$; Figure 2$)$, or a larger relative $\mathrm{CH}\left(\mathrm{X}^{2}{ }_{1}=29.032, p<0.001\right.$; Figure 2$)$. The larger competitor's chances of victory also increased further as the difference in relative $C L$ of the competitors increased (estim. $=1.856, \mathrm{z}=2.152, p=0.031$ ). Finally, morphology impacted the risk of the behavior, as an interaction was more likely to result in a competitor falling into the water as the difference in the relative CL between competitors decreased (estim. $=-2.775, \mathrm{z}=-1.129, p=0.015)$.

While foundation structure and crab morphology had large effects on ritual aggression behavior and its outcomes, they were not the only factors to impact this behavior or its costs. In fact, the only factor that increased the likelihood that the costliest behavior (fighting) would occur during the ritual progression was a longer interaction (estim. $=0.022, \mathrm{z}=2.946, p=0.003$ ), while no measured factor impacted the duration of fighting behavior. Similarly, despite increasing the incidence of the low-cost shield posture behavior (estim. $=0.022, \mathrm{z}=2.946, p=0.035$ ), longer interactions were more 
likely to be risky, as the likelihood of a competitor falling into the water increased with interaction duration (estim. $=0.050, \mathrm{z}=3.862, p<0.001$ ). Further, inter-habitat interactions were more often won by crabs originating from the salt marsh $\left(\mathrm{X}^{2}{ }_{1}=18.667, p<0.001\right.$; Figure 2$)$ than those originating from mangroves $\left(\mathrm{X}^{2}{ }_{1}=6.439, p=0.011\right)$ and docks $\left(\mathrm{X}^{2}{ }_{1}=5.121, p=0.024\right)$. However, originating from the dock habitat provided no advantage over those from the mangrove $\left(\mathrm{X}^{2}{ }_{1}=0.077, p=0.782\right)$. Instigators of interactions were also more likely to win $\left(\mathrm{X}^{2}{ }_{1}=12.500, p<0.001\right.$; Figure 2$)$ but instigating did not provide an advantage to smaller crabs $\left(\mathrm{X}^{2}{ }_{1}=0.692, p=0.405\right)$. In addition, neither the relative size of the competitor (smaller of larger) $\left(\mathrm{X}^{2}{ }_{1}=1.034, p=0.309\right)$ nor its habitat of origin (salt marsh: $\mathrm{X}^{2}{ }_{1}=0.032, p=0.858$; dock: $\mathrm{X}^{2}{ }_{1}=1.485, p=0.223$; mangrove: $\mathrm{X}^{2}{ }_{1}=2.314, p=0.128$ ) were associated with the likelihood of a crab to instigate.

\subsection{Claw Morphology}

All measures of claw size (CL, CH, CH:CL) increased with crab size $(p<0.001$ for each; CL: estim. $=0.806, \mathrm{z}=86.806$; CH: estim. $=0.587, \mathrm{z}=64.614 ; \mathrm{CH}: \mathrm{CL}$ : estim. $=0.013, \mathrm{z}=64.614$; Figure 3). The morphological relationships between body size and each measure of claw size varied by habitat (Table 3). See Supplementary Table S2 for measured body and claw sizes in each habitat.

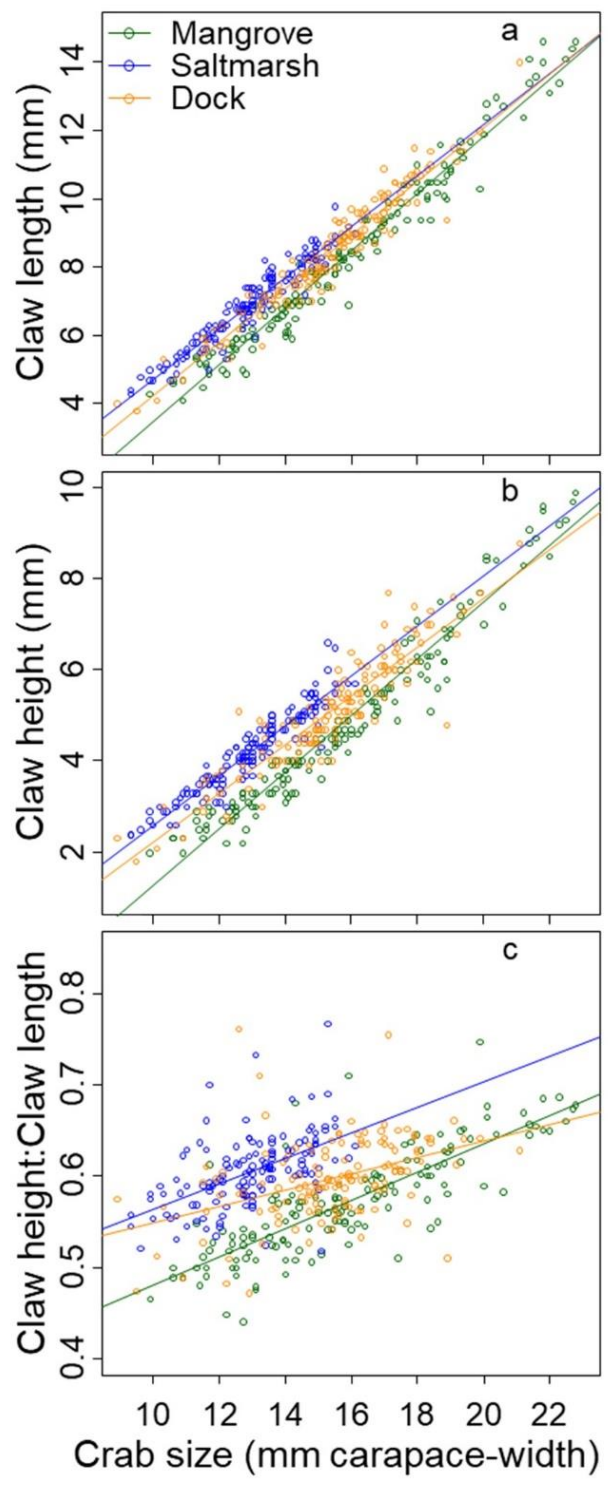

Figure 3. Relationships between A. pisonii size and (a) claw length, (b) claw height, and (c) claw-height:claw-length ratio. 
Table 3. Relationships between crab body size and each measure or claw size in each habitat.

\begin{tabular}{cccc}
\hline Measure of Claw Size & Habitat & Relationship to Body Size & Adjusted $\mathbf{r}^{\mathbf{2}}$ \\
\hline \multirow{3}{*}{ Claw Length (CL) } & Mangrove & $\mathrm{CL}=0.832 \times$ body_size -4.817 & 0.964 \\
& Salt Marsh & $\mathrm{CL}=0.745 \times$ body_size -2.717 & 0.916 \\
& Dock & $\mathrm{CL}=0.781 \times$ body_size -3.536 & 0.928 \\
\hline \multirow{2}{*}{ Claw Height $(\mathrm{CH})$} & Mangrove & $\mathrm{CH}=0.620 \times$ body_size -4.932 & 0.947 \\
& Salt Marsh & $\mathrm{CH}=0.545 \times$ body_size -2.841 & 0.890 \\
& Dock & $\mathrm{CH}=0.534 \times$ body_size -3.123 & 0.836 \\
\hline \multirow{2}{*}{ Claw Height-Claw } & Mangrove & $\mathrm{CH}: \mathrm{CL}=0.015 \times$ body_size +0.327 & 0.660 \\
Length Ratio $(\mathrm{CH}: \mathrm{CL})$ & Salt Marsh & $\mathrm{CH}: \mathrm{CL}=0.014 \times$ body_size +0.424 & 0.288 \\
& Dock & $\mathrm{CH}: \mathrm{CL}=0.009 \times$ body_size +0.458 & 0.173 \\
\hline
\end{tabular}

Unexpectedly crabs from the salt marsh had relatively larger claws, in all measures, than conspecifics from either the dock or mangrove habitats $(p<0.001$ for all; vs dock: CL: estim. = $-0.417, \mathrm{z}=-7.153, \mathrm{CH}$ : estim. $=-0.549, \mathrm{z}=-9.640, \mathrm{CH}: \mathrm{CL}:$ estim. $=-0.041, \mathrm{z}=-8.586$; vs mangrove: CL: estim. $=-0.898, \mathrm{z}=-15.113, \mathrm{CH}$ : estim. $=-1.020, \mathrm{z}=-17.533, \mathrm{CH}: \mathrm{CL}$ : estim. $=-0.073$, $\mathrm{z}=-14.937$; Figure 3) while crabs from the dock habitat had relatively larger claws than conspecifics from the mangrove $(p<0.001$ for all; CL: estim. $=-0.482, z=-9.106, \mathrm{CH}$ : estim. $=-0.471, \mathrm{z}=-9.109$, CH:CL: estim. $=-0.320, \mathrm{z}=-7.329$; Figure 3$)$, which was consistent with expectations.

\section{Discussion}

Structural differences between foundation species impacted A. pisonii ritualistic aggression behavior, its outcomes, and its costs in unexpected ways (Figure 4). Despite the limited surface area they provide, interactions were more likely to occur on marsh structure than either dock or mangrove structure. Even the progression of the behavior was altered by the structure on which it was performed. Interactions on mangrove structure were more likely to include the low-cost shield posturing than other structure types where crabs progressed more quickly to higher-cost behaviors. Losing competitors were also less likely to mount a conciliatory retreat on marsh structure than mangroves, possibly due to the reduced structural area provided by marsh grasses for retreat/evasion behaviors [33] and potentially increasing the possibility of reigniting the interaction. These reductions of ritual complexity and tendencies to progress more quickly to higher-cost behaviors could increase the chance of injury and energetic cost of the interaction [34] thus negating some of the benefit of ritualizing aggressive behavior.

These tendencies to progress more quickly to high-cost behaviors on structure from the colonized ecosystem may reflect a difference in the cost-benefit calculation from the mangrove habitat. A competitor was more likely to fall into the water on dock and marsh structure than the mangrove, likely due in part to the decreased footing they provide (low surface area on marsh structure, vertical nature of docks). This would elevate the potential danger of an interaction by increasing the chance that one or both competitors are exposed to aquatic predation, which is also higher in the colonized ecosystem [33]. Thus, as instigators of interactions are more likely to win independent of their size or habitat of origin, and as longer interactions are more likely to result in the loser falling into the water, the higher danger of interactions on marsh and dock structure may encourage crabs to act more aggressively in the interest of increasing their chance of victory [31,32]. While ritualistic aggression is important to the division of resources in this species, it evolved in the mangrove habitat where, like many ritualized interactions, it is relatively low-cost [16]. If the structural make-up of the colonized habitats increases these costs, it could alter the ability of this species to successfully establish a social hierarchy without significant losses. 


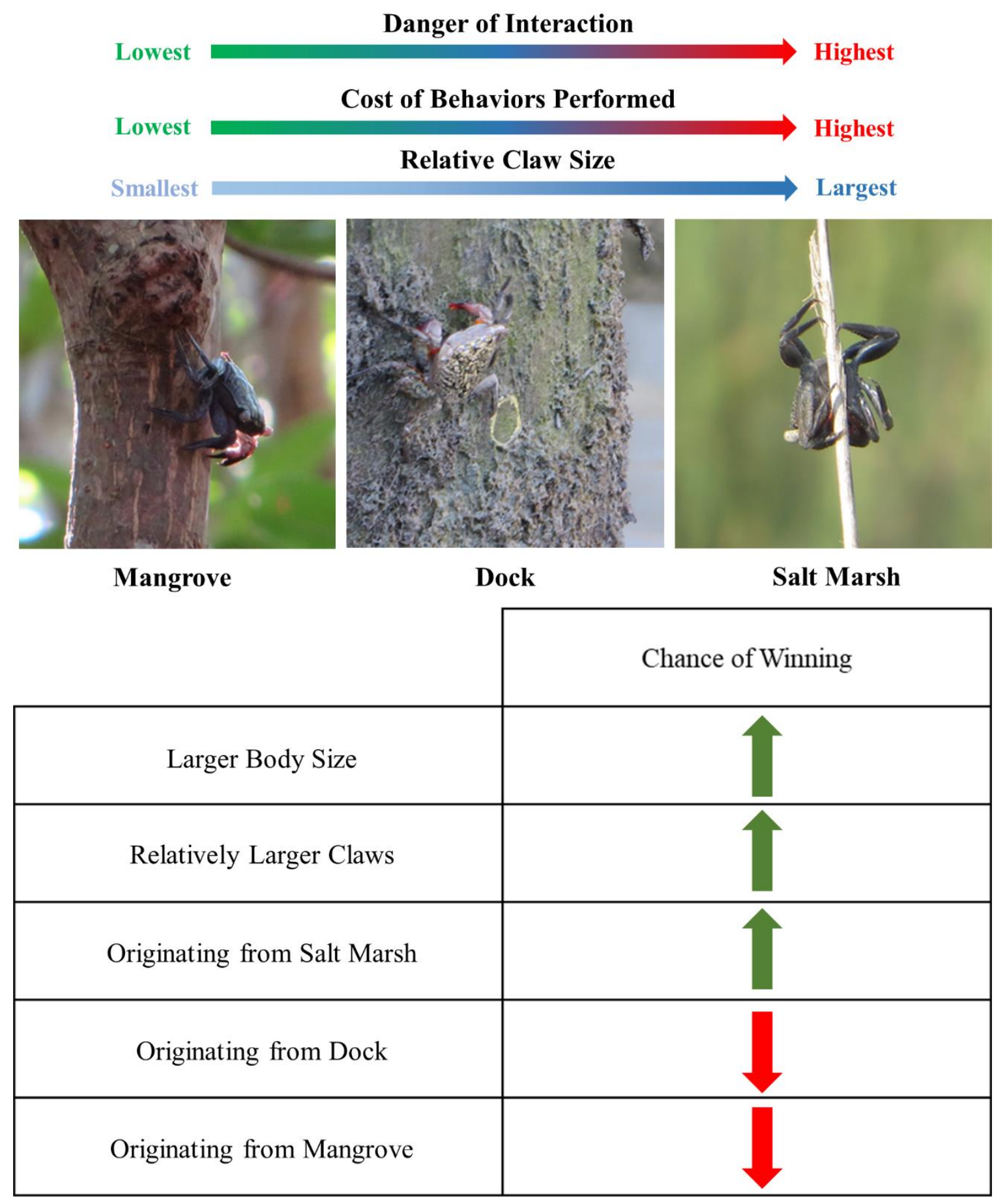

Figure 4. Summary of the effects of foundation structure and morphology on A. pisonii ritualistic aggression behavior. A green arrow indicates a higher chance of winning an interaction while a red arrow indicates a lower chance of winning.

Despite the similar danger of falling into water, docks did lower the incidence of interaction compared to marsh structure. This suggests that while the cost of interactions on dock structure is relatively high, the increased structure provided by docks increases the ability of competitors to avoid aggressive interactions through avoidance and retreat [16], an option which may be difficult on the limited structural area of marsh grasses. The increased risk of interactions on docks relative to the mangrove may simply be a reflection of the vertical nature of this structure, which could also be experienced during interactions taking place on mangrove trunks. However, mangroves provide 
a higher occurrence of more complex horizontal structure (in the form of prop-roots and branches) than either marsh grasses or docks. Competitors were often observed using the complex structure of mangrove roots to retreat after an interaction or avoid confrontation altogether. This ability is drastically reduced in both the dock and salt marsh habitats where crabs are limited in the above-water area in which to retreat. On docks, losers may only escape by moving around a piling, which does not preclude chasing by the winner, while salt marsh grasses provide nearly no area for retreat short of jumping into the water. While both docks and mangroves provide more structural area for retreat than could be fully replicated in our assays, the structural complexity of docks is still far lower than that of mangrove roots and branches. Thus, while docks may provide improved structure for ritualized aggression over marsh grasses, they clearly do not provide a perfect analogue to the historic mangrove habitat for the purposes of maintaining this behavior.

In addition to foundation species structure, crab morphology impacted ritualized aggression interactions and their outcomes (Figure 4). As has been observed in numerous species [27,35,36], larger individuals and those with larger weaponry (claws) were more likely to win interactions. Increases in size and relative claw sizes were also associated with costlier behavioral steps (i.e., less shield posture, more display), while decreasing differences in relative claw size increased the likelihood that a competitor would fall in the water. These results fit both theory and observations in other species that the more evenly matched the competitors, the more likely an interaction is to escalate and become costly [37-40]. However, while the impacts of morphology on interactions were largely predictable, the differences in claw morphology between habitats were unexpected and could have consequences for this behavior in the colonized salt marsh ecosystem.

Crabs originating from the dock habitat had relatively larger claws than conspecifics from the mangrove but the relative claw size of $A$. pisonii from in the salt marsh proper was larger still. While the large claws of crabs from docks may be explained by a diet high in animal material [14,29], the low-quality diet A. pisonii experiences in the salt marsh [14] makes the mechanism behind their large claws uncertain. Larger claws may provide an advantage in grasping the limited structure of grass stalks, a problem not faced by conspecifics in other habitats. Further, the relatively small size of crabs in the salt marsh compared to the mangrove and dock habitats [14] may suggest that they have a slower growth rate. If body size is more plastic than claw size, this could result in relatively larger claws. However, these hypotheses are beyond the scope of this study.

It is also possible that the observed changes to ritualized aggression are themselves driving the increase in claw size. Relatively larger claws increase the probability of winning an aggressive interaction and, despite previous assertions [16], may be even more important than overall size [27]. In fact, the $\mathrm{X}^{2}$ values associated with larger-clawed competitors winning interactions were more than 5 -fold higher than that associated with larger crabs winning. This suggests that for A. pisonii, relative claw size is far more important in determining the winner of ritualized interactions. This benefit of large claws is further visible in the tendency of crabs from the salt marsh to win inter-habitat interactions regardless of relative size, habitat of competitor, or structural type. Thus, the increase in claw size may be a plastic response to the increased danger and prevalence of aggressive interactions in the salt marsh. If this is the case, it would signify a shift to relatively greater investment into claw growth at the expense of body size and other energetic needs. However, a full test of this hypothesis would require a complete exploration of $A$. pisonii energetics, which was beyond the scope of this study. Whether this shift in morphology is a response to or a result of the observed differences in behavior between habitats, it has implications for the ritualistic aggression behavior and the ecology of this species.

While our study was primarily designed to determine the impact of foundational structure on A. pisonii ritual aggression, the results detailing the impacts of crab morphology on this behavior provide an opportunity to explore the assessment model employed by this species during combat. During aggressive interactions, three primary modes of assessment are possible. In self-assessment, individuals gauge their ability to win using only information about their own fighting abilities [41]. 
In cumulative assessment, individuals gauge their ability to win both on their own abilities and on the damage inflicted by their opponent [41,42]. In mutual assessment, both contestants assess their opponent's potential relative to their own [15,41,43]. As the size of competitors did not influence the duration of interactions, and as both body and claw size were positively correlated with the likelihood of winning, it is likely that $A$. pisonii engages in mutual assessment rather than either self-assessment or cumulative assessment [41,44]. In particular, as previously suggested by Warner [16], the ritual progression employed by A. pisonii suggests sequential assessment $[15,16]$. Further experiments are required to confirm this hypothesis.

As species continue to shift into novel ecosystems, it is vital to understand how interactions with novel foundation species and other ecosystem engineers impact their behavior. The alteration of A. pisonii ritualized aggression, and its potential costs, highlights the potential impact that changes to foundation species structure can have on a colonizing population. The morphological and behavioral changes observed in A. pisonii further demonstrate how the impacts experienced by range shifters due to novel foundation species can interact in unexpected ways. Thus, as climate-mediated colonizations of novel ecosystems become more common, it will be important to understand how multiple impacts of these colonizations interact to alter the ecology, behavior, and life history of range-shifting species.

Supplementary Materials: The following are available online at http://www.mdpi.com/1424-2818/11/1/6/s1, Table S1: Full statistical result of the simplest model by AIC of all aggression assay tests, Table S2: Morphological measurements of crabs from each habitat.

Author Contributions: Conceptualization, Z.J.C. and B.D.G.; Data curation, Z.J.C.; Formal analysis, Z.J.C.; Funding acquisition, Z.J.C.; Investigation, Z.J.C., S.K.N. and I.C.W.; Methodology, Z.J.C. and B.D.G.; Project administration, Z.J.C. and B.D.G.; Resources, Z.J.C.; Supervision, B.D.G.; Visualization, Z.J.C. and B.D.G.; Writing —original draft, Z.J.C.; Writing—review \& editing, Z.J.C. and B.D.G.

Funding: This work was supported by an Animal Behavior Society Student Research Grant and a SPARC Graduate Research Grant from the Office of the Vice President for Research at the University of South Carolina.

Acknowledgments: The authors thank the Smithsonian Marine Station at Fort Pierce, FL and the Guana Tolomato Matanzas National Estuarine Research Reserve of St. Augustine, FL for aid and assistance. This work was supported by an Animal Behavior Society Student Research Grant and a SPARC Graduate Research Grant from the Office of the Vice President for Research at the University of South Carolina. This is Smithsonian Marine Station contribution number 1103.

Conflicts of Interest: The authors declare no conflict of interest.

\section{References}

1. Jones, C.G.; Lawton, J.H.; Shachak, M. Organisms as ecosystem engineers. Oikos 1994, 69, 373-386. [CrossRef]

2. Dayton, P.K. Toward an understanding of community resilience and the potential effects of enrichments to the benthos at McMurdo Sound, Antarctica. In Proceeding of the Colloquium on the Conservation Problems in Antarctica; Parker, B.C., Ed.; Allen Press: Lawrence, KS, USA, 1972; pp. 81-96.

3. Ellison, A.M.; Bank, M.S.; Clinton, B.D.; Colburn, E.A.; Elliot, K.; Webster, J.R. Loss of foundation species: Consequences for the structure and dynamics of forested ecosystems. Front. Ecol. Environ. 2005, 3, 479-486. [CrossRef]

4. Cannizzo, Z.J.; Griffen, B.D. Changes in behaviour patterns by mangrove tree crabs following climate-induced range shift into novel habitat. Anim. Behav. 2016, 121, 79-86. [CrossRef]

5. Bruschetti, M.; Bazterrica, C.; Luppi, T.; Iribarne, O. An invasive intertidal reef-forming polychaete affect habitat use and feeding behavior of migratory and local birds in a SW Atlantic coastal lagoon. J. Exp. Mar. Biol. Ecol. 2009, 375, 76-83. [CrossRef]

6. Jayadevan, A.; Mukherjee, S.; Vanak, A.T. Bush encroachment influences nocturnal rodent community behaviour in a semi-arid grassland in Grujarat, India. J. Arid Environ. 2018, 153, 32-38. [CrossRef]

7. Gribben, P.E.; Wright, J.T. Habitat-former effects on prey behaviour increase predation and non-predation mortality. J. Anim. Ecol. 2014, 83, 388-396. [CrossRef] [PubMed]

8. O'Brien, B.S.; Mello, K.; Litterer, A.; Dijkstra, J.A. Seaweed structure shapes trophic interactions: A case study using a mid-trophic level fish species. J. Exp. Mar. Biol. Ecol. 2018, 506, 1-8. [CrossRef] 
9. Schweiger, O.; Settle, J.; Kudrna, O. Climate change can cause spatial mismatch of trophically interacting species. Ecology 2008, 89, 3472-3479. [CrossRef] [PubMed]

10. Walther, G.R. Community and ecosystem responses to recent climate change. Philos. Trans. R. Soc. B. Biol. Sci. 2010, 365, 2019-2024. [CrossRef] [PubMed]

11. Wong, B.B.M.; Candolin, U. Behavioral responses to changing environments. Behav. Ecol. 2015, 26, 665-673. [CrossRef]

12. Riley, M.E.; Johnston, C.A.; Feller, I.C.; Griffen, B.D. Range expansion of Aratus pisonii (mangrove tree crab) into novel vegetative habitats. Southeast. Nat. 2014, 13, N43-N48. [CrossRef]

13. Riley, M.E.; Griffen, B.D. Habitat-specific differences alter traditional biogeographic patterns of life history in a climate-change induced range expansion. PLoS ONE 2017, 12, e0176263. [CrossRef] [PubMed]

14. Cannizzo, Z.J.; Dixon, S.R.; Griffen, B.D. An anthropogenic habitat within a suboptimal colonized ecosystem provides improved conditions for a range-shifting species. Ecol. Evol. 2018, 8, 1524-1533. [CrossRef] [PubMed]

15. Enquist, M.; Leimar, O. Evolution of fighting behaviour: Decision rules and assessment of relative strength. J. Theor. Biol. 1983, 102, 387-410. [CrossRef]

16. Warner, G.F. Behaviour of two species of grapsid crab during intraspecific encounters. Behaviour 1970, 36, 9-19. [CrossRef]

17. Greene, M.J.; Mason, R.T. Courtship, mating, and male combat of the brown tree snake, Boiga irregularis. Herpetologica 2000, 56, 166-175.

18. Slater, K.Y.; Schaffner, C.M.; Aureli, F. Female-directed male aggression in wild Ateles geoffroyi ssp. yucatanensis. Int. J. Primatol. 2008, 29, 1657-1669. [CrossRef]

19. Theil, M.; Lovrich, G.A. Agonistic behaviour and reproductive biology of squat lobsters. In Biology of Squat Lobsters; Poore, G.C.B., Ahyong, S.T., Taylor, J., Eds.; Csiro Publishing: Clayton, Vic, Australia, 2011; pp. 233-247.

20. Schofield, G.; Katselidis, K.A.; Pantis, J.D.; Dimopoulos, P.; Hays, G.C. Female-female aggression: Structure of interaction and outcome in loggerhead sea turtles. Mar. Ecol. Prog. Ser. 2007, 336, 267-274. [CrossRef]

21. Fernandez, A.A.; Fasel, N.; Knörnschild, M.; Richner, H. When bats are boxing: Aggressive behaviour and communication in male Seba'short-tailes fruit bat. Anim. Behav. 2014, 98, 149-156. [CrossRef]

22. Mercier, J.L.; Lenoir, A.; Dejean, A. Ritualised versus aggressive beahviours displayed by Polrhachis laboriosa (F. Smith) during intraspecific competition. Behav. Process. 1997, 41, 36-50. [CrossRef]

23. Skaggs, R.; Jackson, J.C.; Toth, A.L.; Schneider, S.S. The possible role of ritualized aggression in the vibration signal of the honeybee, Apis mellifera. Anim. Behav. 2014, 98, 103-111. [CrossRef]

24. Trisko, R.K.; Smuts, B.B. Dominance relationships in a group of domestic dogs (Canis lupus famililaris). Behaviour 2015, 152, 677-704. [CrossRef]

25. Wilczynski, W.; Black, M.P.; Salem, S.J.; Ezeoke, C.B. Behavioural persistence during an agonistic encounter differentiates winners from losers in green anole lizards. Behaviour 2015, 152, 563-591. [CrossRef]

26. Warner, G.F. The life history of the Mangrove Tree Crab, Aratus pisonii. J. Zool. 1967, 153, 321-335. [CrossRef]

27. Sneddon, L.U.; Huntingford, F.A.; Taylor, A.C. Weapon size versus body size as a predictor of winning in fights between shore crabs, Carcinus maenas (L.). Behav. Ecol. Sociobiol. 1997, 41, 237-242. [CrossRef]

28. Brian, J.V.; Fernandes, T.; Ladle, R.J.; Todd, P.A. Patterns of morphological and genetic variability in UK populations of the shore crab, Carcius maenas Linnaeus, 1758 (Crustacea: Decapoda: Brachyura). J. Exp. Mar. Biol. Ecol. 2006, 329, 47-54. [CrossRef]

29. Smith, L.D.; Palmer, A.R. Effects of manipulated diet on size and performance of bracyuran crab claws. Science 1994, 264, 710-712. [CrossRef]

30. De Lemos Santana, J.; Dos Santos Calado, T.C.; de Alemeids Alves-Júnior, F.; de Oliveira, M.A.; de Sá Leitão Câmara de Araújo, M. Populational structure and sexual maturity of Aratus pisonii (H. Milne Edwarrds, 1837) (Crustacea, Decapoda, Sesarmidae) in the estuarine channels of Mundaú Lagoon, Northeastern Brazil. Panam. J. Aquat. Sci. 2018, 13, 1-12.

31. Neat, F.C.; Huntingford, F.A.; Beveridge, M.M.C. Fighting and assessmet in male sichlid fish: The effects of asymmetries in gonadal state and body size. Anim. Behav. 1998, 55, 883-891. [CrossRef]

32. Hofmann, H.A.; Schildberger, K. Assessment of strength and wiliness to fight during aggressive encounters in crickets. Anim. Behav. 2001, 62, 337-348. [CrossRef] 
33. Johnston, C.A.; Smith, R.S. Vegetation structure mediates a shift in predator avoidance behavior in a range-edge population. Behav. Ecol. 2018, 29, 1124-1131. [CrossRef]

34. Huxley, J.A. A discussion on ritualization of beahviour in animals and man. R. Soc. 1966, 4, 1-60.

35. Caldwell, R.L.; Dingle, J. The influence of size differential on agonistic encounters in the mantis shrimp Gonodactylus viridis. Behaviour 1979, 69, 255-264. [CrossRef]

36. Gabbanini, F.; Gherardi, F.; Vannini, M. Force and dominance in the agonistic behavior of the freshwater crab Potamon fluviatile. Aggress. Behav. 1995, 21, 451-462. [CrossRef]

37. Parker, G.A. Assessment strategy and the evolution of fighting behaviour. J. Theor. Biol. 1974, 74, $223-243$. [CrossRef]

38. Smith, I.P.; Huntingford, F.A.; Atkinson, R.J.A.; Taylor, A.C. Strategic decisions during anostic behaviour in the velvet swimming crab, Necora puber (L.). Anim. Behav. 1994, 47, 885-894. [CrossRef]

39. Maynard Smith, J.; Parker, G.A. The logic of asymmetric contests. Anim. Behav. 1976, 24, 159-175. [CrossRef]

40. Poole, J.H. Announcing intent: The aggressive state of musth in African elephants. Anim. Behav. 1989, 37, 140-152. [CrossRef]

41. Arnott, G.; Elwood, R.W. Assessment of fighting ability in animal contests. Anim. Behav. 2009, 77, 991-1004. [CrossRef]

42. Payne, R.J.H. Gradually escalating fights and displays: The cumulative assessment model. Anim. Behav. 1998, 56, 651-662. [CrossRef]

43. Enquist, M.; Leimar, O.; Ljungberg, T.; Mallner, Y.; Segerdahl, N. A test of the sequential assessment game-Fighting in the cichlid fish Nannacara anomala. Anim. Behav. 1990, 40, 1-14. [CrossRef]

44. Taylor, P.W.; Elwood, R.W. The mismeasure of animal contests. Anim. Behav. 2003, 65, 1195-1202. [CrossRef]

(C) 2019 by the authors. Licensee MDPI, Basel, Switzerland. This article is an open access article distributed under the terms and conditions of the Creative Commons Attribution (CC BY) license (http:/ / creativecommons.org/licenses/by/4.0/). 